\title{
CORRIGENDUM
}

\section{Validation of the instrumented evaluation of spatio-temporal gait parameters in patients with motor incomplete spinal cord injury}

AI Pérez-Sanpablo, J Quinzaños-Fresnedo, R Loera-Cruz, I Quiñones-Uriostegui, G Rodriguez-Reyes and R Pérez-Zavala

Spinal Cord (2017) 55, 712; doi:10.1038/sc.2017.51

Correction to: Spinal Cord (2017) 55, 699-704; doi:10.1038/ sc.2017.4; published online 28 February 2017

Since the publication of this paper, the authors have noted that the author GR Reyes should have been listed as G Rodriguez-Reyes. The PDF and HTML versions of the paper have been modified accordingly.

The authors apologise for any inconvenience caused. 